DOI: $10.29303 /$ jrpb.v8i2.190

ISSN 2301-8119, e-ISSN 2443-1354

Tersedia online di http://jrpb.unram.ac.id/

\title{
ANALISIS NILAI TAMBAH PRODUK AGROINDUSTRI TEMPE DI KECAMATAN SUKAMULIA, KABUPATEN LOMBOK TIMUR
}

\author{
Analysis of Added Value on Tempe Agroindustrial Product \\ in Sukamulia Regency, East Lombok District
}

Agriananta Fahmi Hidayat*), Surya Abdul Muttalib

Program Studi Teknik Pertanian, Fakultas Teknologi Pangan dan Angroindustri

Universitas Mataram, J1. Majapahit No 62, Mataram 83125, Indonesia

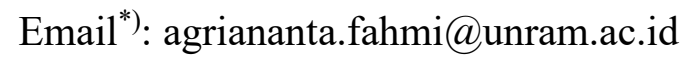

Diterima: Juli 2020

Disetujui: September 2020

\begin{abstract}
Tempe processing is one of potential agroindustrial product to be developed because as much as $50 \%$ of Indonesian soybean consumption is used to produce tempe, $40 \%$ tofu, and $10 \%$ in the form of other products. Tempe agroindustry in Sukamulia Regency can have an economic impact on businesses due to the market is still wide open. Agroindustrial activities are affected by production costs. The use of production costs aims to provide added value to soybeans into tempe and increase income and employment. This article aimed to analyze of the added value of tempe agroindustrial products using the Hayami method. There were three variables used in this model, i.e., (1) input-output and price; (2) revenue and profits; (3) margin. Based on the analysis, the costs required for one tempe production cycle was Rp 146,000 and the income earned in one production cycle was $R p$ 160,000. The added value obtained by tempe agroindustry entrepreneurs was Rp 6,160 per kilogram with a total tempe production of 16 kilograms in one production process.
\end{abstract}

Keywords: tempe processing; Hayami method; added-value analysis

\begin{abstract}
ABSTRAK
Pengolahan tempe adalah salah satu produk agroindustri yang potensial untuk dikembangkan karena sebanyak 50\% dari konsumsi kedelai Indonesia dijadikan untuk memproduksi tempe, $40 \%$ tahu, dan 10\% dalam bentuk produk lain. Agroindustri tempe di Kecamatan Sukamulia, Kabupaten Lombok Timur, Provinsi Nusa Tenggara Barat dapat memberikan dampak ekonomi terhadap pelaku usaha dikarenakan pasar yang ada masih terbuka lebar. Kegiatan agroindustri dipengaruhi oleh biaya produksi. Penggunaan biaya produksi bertujuan untuk memberikan nilai tambah pada kedelai menjadi tempe dan meningkatkan pendapatan dan lapangan kerja. Penelitian ini bertujuan menganalisis nilai tambah produk agroindustri tempe dengan metode Hayami. Terdapat tiga variable yang digunakan pada metode ini, yaitu (1) output input dan harga; (2) penerimaan dan keuntungan, dan (3) margin. Dari hasil analisis diperoleh biaya yang dikeluarkan untuk satu kali siklus produksi tempe adalah Rp 146.000 dan pendapatan yang diperoleh dalam satu kali siklus produksi Rp 160.000. Nilai tambah yang diperoleh pengusaha
\end{abstract}


agroindustri tempe, yaitu $\mathrm{Rp} 6.160$ per kilogram dengan total produksi tempe 16 kilogram dalam satu kali proses produksi.

Kata kunci: analisis nilai tambah; metode Hayami; pengolahan tempe

\section{PENDAHULUAN}

Agroindustri merupakan industri pengolahan produk yang meningkatkan nilai tambah pada produk-produk pertanian (Wachdijono \& Julhan, 2019). Kedelai di Indonesia dimanfaatkan sebanyak 50\% untuk produksi tempe, $40 \%$ produksi tahu, dan $10 \%$ dalam bentuk produk lain (seperti tauco, kecap, dan lain-lain), sehingga pengolahan tempe bisa menjadi salah satu produk agroindustri yang potensial untuk dikembangkan. Konsumsi tempe rata-rata per orang per tahun di Indonesia saat ini diperkirakan mencapai sekitar 6,45 kg (Badan Standardisasi Nasional, 2012).

Tempe merupakan makanan tradisional yang sangat familiar di Indonesia, tempe memiliki kandungan gizi yang baik bagi kesehatan diantaranya kandungan zat besi, flavonoid yang bersifat antioksidan sehingga mampu untuk menurunkan tekanan darah (Amani et al., 2014). Tempe juga memiliki kandungan kalsium yang tinggi, sehingga mampu untuk mencegah terjadinya osteoporosis (Yoo et al., 2014)

Hadirnya agroindustri tempe di Kecamatan Sukamulia, Kabupaten Lombok Timur, Provinsi Nusa Tenggara Barat dapat memberikan dampak ekonomi terhadap pelaku usaha dikarenakan pasar yang ada masih terbuka lebar. Besarnya biaya produksi dapat mempengaruhi kegiatan agroindustri, biaya produksi bertujuan untuk memberikan nilai tambah pada kedelai yang dikonversi menjadi tempe dan meningkatkan pendapatan serta lapangan kerja.

Metode nilai tambah merupakan salah satu indikator terpenting yang dihasilkan dari kegiatan ekonomi perusahaan dan mencerminkan kekuatan ekonomi (Aji et al., 2018). Pendekatan Hayami adalah salah satu metode yang dapat digunakan untuk mengevaluasi indikator tersebut.

Penelitian untuk mengetahui nilai tambah tempe yang diproduksi di Kecamatan Sukamulia belum pernah dilakukan sebelumnya. Berdasarkan latar belakang tersebut, penelitian ini bertujuan untuk menganalisis nilai tambah produk agroindustri tempe dengan metode Hayami.

\section{METODE PENELITIAN}

Data-data yang digunakan dalam penelitian ini terdiri dari data primer dan data sekunder. Data primer diperoleh dengan pengamatan dan pencatatan langsung di lokasi usaha meliputi data kebutuhan bahan baku, dan data masukan dan keluaran yang lain yang diambil dalam rata-rata satu siklus produksi harian selama satu bulan pada tahun 2018. Data sekunder diperoleh dari literatur.

Data yang didapatkan pada penelitian ini diolah di Laboratorium Analisis Sistem dan Komputer, Fakultas Teknologi Pangan dan Agroindustri Universitas Mataram, dengan menggunakan software Microsoft Office. Data primer didapatkan dari lokasi produksi tempe di kecamatan Sukamulia, pemilihan lokasi dilakukan dengan sengaja (purposive sampling). Responden yang dipilih secara sengaja adalah yang dianggap mengetahui dan membantu menjawab permasalahan (Husniah et al., 2019).

Analisis data dilakukan menggunakan metode Hayami, dengan pendekatan nilai tambah. Nilai tambah dihitung dengan memperhatikan interaksi antara pelaku dengan tujuan masing-masing (Pamungkassari et al., 2018). Perhitungan analisis nilai tambah dengan model Hayami menggunakan tiga variable, yaitu (1) output input dan harga, (2) penerimaan dan keuntungan, (3) margin. 
Kriteria nilai tambah ditetapkan sebagai berikut: jika nilai tambah $>0$, maka produksi pengolahan tempe memberikan nilai tambah, dan jika nilai tambah $<0$, maka produksi pengolahan tempe tidak memberikan nilai tambah (Febriyanti et al., 2017).

\section{HASIL DAN PEMBAHASAN}

Usaha agroindustri tempe merupakan usaha skala UMKM (Usaha Mikro Kecil Menengah) dengan sumber daya terbatas serta produksi yang terbatas. UMKM agroindustri tempe didirikan oleh kelompok guru ngaji dengan melihat pasar kebutuhan tempe yang tinggi di Kecamatan Sukamulia. Selain itu, di daerah ini belum terdapat sentra produksi tempe.

Data yang didapatkan dari responden di daerah ini selanjutnya diolah mengacu pada metode Hayami (Tabel 1). Adapun biaya yang dibutuhkan oleh usaha agroindustri tempe ini adalah biaya tetap, biaya variabel, dan biaya investasi. Biayabiaya tersebut ditunjukkan pada Tabel 2 .

Berdasarkan penelitian, agroindustri tempe di Kecamatan Sukamulia dapat memenuhi rata-rata permintaan per hari sebanyak 80 bungkus tempe dengan harga
Rp 2.000 per bungkus. Kebutuhan bahan baku per hari (1 siklus produksi) adalah 10 $\mathrm{kg}$ kedelai yang mampu menghasilkan $16 \mathrm{~kg}$ tempe. Sehingga, rata-rata pendapatan usaha agroindustri tempe adalah Rp 160.000.

Tabel 2. Biaya Investasi, Biaya Tetap dan Biaya Variabel

\begin{tabular}{lr}
\multicolumn{1}{c}{ BIAYA } & NILAI (Rp) \\
\hline BIAYA INVESTASI & \\
Peralatan & $\mathbf{1 1 , 8 2 0 , 0 0 0}$ \\
BIAYA & $\mathbf{5 2 , 5 6 0 , 0 0 0}$ \\
VARIABEL & \\
BIAYA TETAP & \\
Penyusutan & $2,293,250$ \\
Peralatan & $4,800,000$ \\
sewa bangunan & $\mathbf{7 , 0 9 3 , 2 5 0}$ \\
\hline TOTAL BIAYA & $\mathbf{7 1 , 4 7 3 , 2 5 0}$ \\
\hline
\end{tabular}

Sumber: Hasil olah data penulis (2020)

Analisis nilai tambah produk pertanian dapat dilakukan dengan perhitungan nilai tambah per kilogram bahan baku untuk per satu siklus produksi Herdiyandi et al., (2017). Hasil analisis nilai tambah pada agroindustri tempe di Kecamatan Sukamulia dapat dilihat pada Tabel 3.

Tabel 1. Perhitungan Nilai Tambah Model Hayami

\begin{tabular}{rlcl}
\hline \multicolumn{1}{c}{ No } & \multicolumn{1}{c}{ Variabel } & Nilai & \multicolumn{1}{c}{ Satuan } \\
\hline Output, Input, Harga & & \\
1 & Output & 1 & $\mathrm{~kg} /$ siklus produksi \\
2 & Input & 2 & $\mathrm{~kg} /$ siklus produksi \\
3 & TK langsung & 3 & $\mathrm{HOK}$ \\
4 & Faktor Konversi & $1 / 2$ & $\mathrm{Kg} / \mathrm{Siklus}$ Produksi \\
5 & Koefisien tenaga kerja & $3 / 2$ & $\mathrm{HOK} / \mathrm{Kg}$ \\
6 & Harga output & & $\mathrm{Rp} / \mathrm{Kg}$ \\
7 & Upah tenaga kerja & $\mathrm{Rp} / \mathrm{HOK}$ \\
\hline
\end{tabular}

\section{Penerimaan dan Keuntungan}

8 Nilai bahan baku

9 Harga input lain

10 Nilai tempe

11 a. Nilai tambah

b. Rasio nilai tambah

$\begin{array}{cl} & \mathrm{Rp} / \mathrm{Kg} \\ & \mathrm{Rp} / \mathrm{Kg} \\ 4 \times 6 & \mathrm{Rp} / \mathrm{Kg} \\ 10-8-9 & \mathrm{Rp} / \mathrm{Kg} \\ 11 \mathrm{a} / 10 & \%\end{array}$


12 a. Pendapatan TK langsung

$$
\begin{array}{lcl}
\text { a. Pendapatan TK langsung } & 5 \times 7 & \mathrm{Rp} / \mathrm{Kg} \\
\text { b. Pangsa tenaga kerja langsung } & 12 \mathrm{a} / 11 \mathrm{a} * 100 & \% \\
\text { a. Keuntungan } & 11 \mathrm{a}-12 \mathrm{a} & \mathrm{Rp} / \mathrm{Kg} \\
\text { b. Tingkat keuntungan } \% & 13 \mathrm{a} / 11 \mathrm{a} * 100 & \% \\
\hline
\end{array}
$$

13 a. Keuntungan

b. Tingkat keuntungan $\%$

Margin

14 Margin

$10-8$
a. Pendapatan TK
$12 \mathrm{a} / 14$
b. Sumbangan input lain
$9 / 14$
c. Keuntungan

\begin{tabular}{|c|c|c|c|}
\hline No & Variabel & Nilai & Satuan \\
\hline \multicolumn{4}{|c|}{ Output, Input, Harga } \\
\hline 1 & Tempe & 16 & $\mathrm{Kg} /$ Siklus Produksi \\
\hline \multirow[t]{3}{*}{2} & Kedelai & 10 & Kg/Siklus Produksi \\
\hline & Ragi & 2 & $\mathrm{Kg} /$ Siklus Produksi \\
\hline & Total Input & 12 & $\mathrm{Kg} /$ Siklus Produksi \\
\hline 3 & Tenaga Kerja & 2 & HOK \\
\hline 4 & Faktor Konversi & 1,33 & Kg/Siklus Produksi \\
\hline 5 & Koefisien TK & 0,17 & $\mathrm{HOK} / \mathrm{Kg}$ \\
\hline 6 & Harga Output (tempe) & 16.000 & $\mathrm{Rp} / \mathrm{Kg}$ \\
\hline 7 & Upah TK & 7.500 & $\mathrm{Rp} / \mathrm{HOK}$ \\
\hline \multicolumn{4}{|c|}{ Penerimaan dan Keuntungan } \\
\hline 8 & Harga Bahan Baku & 7.800 & $\mathrm{Rp}$ \\
\hline 9 & Input Lain & 2.000 & $\mathrm{Rp}$ \\
\hline 10 & Nilai Output & $21.333,33$ & $\mathrm{Rp}$ \\
\hline \multirow[t]{2}{*}{11} & a. Nilai Tambah & $11.533,33$ & $\mathrm{Rp}$ \\
\hline & b. Rasio Nilai Tambah & 54 & $\%$ \\
\hline \multirow[t]{2}{*}{12} & a. Pendapatan TK & $1.250,00$ & $\mathrm{Rp}$ \\
\hline & b. Pangsa TKL & 11 & $\%$ \\
\hline \multirow[t]{2}{*}{13} & a. Keuntungan & $10.283,33$ & $\mathrm{Rp}$ \\
\hline & b. Tingkat Keuntungan & 89 & $\%$ \\
\hline \multicolumn{4}{|l|}{ Margin } \\
\hline 14 & Margin & $13.533,33$ & \\
\hline & Pendapatan TK & 9 & $\%$ \\
\hline & Sumbangan & 15 & $\%$ \\
\hline & Keuntungan & 76 & $\%$ \\
\hline
\end{tabular}
$13 \mathrm{a} / 14$

Sumber: Hayami et al. (1987)s

Tabel 3. Hasil Perhitungan Analisis Nilai Tambah Tempe

Sumber: Hasil olah data penulis (2020)

Dari Tabel 3 dapat dilihat bahwa dari satu siklus produksi tempe digunakan bahan baku kedelai sebanyak $10 \quad \mathrm{~kg}$ yang menghasilkan tempe sebanyak $16 \mathrm{~kg}$. Dari data tersebut didapatkan nilai faktor konversi sebesar $1,33 \mathrm{~kg} /$ produksi, yang 
berarti $1 \mathrm{~kg}$ penggunaan bahan baku menghasilkan $1,33 \mathrm{~kg}$ tempe.

Harga input diperoleh dari data kebutuhan bahan baku produksi tempe yaitu kedelai dan ragi sebesar Rp 12.000 per kg per siklus produksi. Berdasarkan analisis nilai tambah agroindustri tempe di Desa Sukamulia, Kecamatan Sukamulia, Kabupaten Lombok Timur, diperoleh nilai tambah positif $(>0)$ dengan rasio nilai tambah 54\%.

Keuntungan diperoleh dengan mengurangi pendapatan tenaga kerja dari nilai tambah. Keuntungan rata-rata diperoleh pengusaha dari pengolahan satu kilogram kedelai menjadi tempe adalah $\mathrm{Rp}$ 10.283,33 dengan persentase tingkat keuntungan $89 \%$. Keuntungan dapat diartikan sebagai nilai tambah bersih yang diterima pengusaha dalam satu kali proses produksi per kilogram bahan baku yang diolah karena sudah tidak mengandung imbalan atau pendapatan tenaga kerja (Sulaiman \& Natawijaya, 2018)

Bedasarkan hasil pengamatan dan perhitungan analisis nilai tambah, proses produksi kedelai menjadi tempe merupakan usaha yang sangat menguntungkan. Hal ini dapat dilihat dari margin sebesar 13.533,33 dan pendapatan tenaga kerja sebesar 9\%. Kegiatan pengolahan produk pertanian menjadi turunannya dapat meningkatkan nilai tambah, meningkatkan keuntungan (Agrie et al., 1997).

\section{KESIMPULAN}

\section{Kesimpulan}

Berdasarkan hasil penelitian, maka diperoleh kesimpulan bahwa nilai tambah yang diperoleh, yaitu $\mathrm{Rp} 11.533$ per kilogram dengan produksi tempe 16 kilogram dalam satu kali proses produksi. Rasio nilai tambah adalah $54 \%$ di atas $50 \%$ termasuk dalam kategori baik, namun diperlukan efisiensi proses produksi untuk menaikkan nilai tambah produk.

\section{UCAPAN TERIMA KASIH}

Penulis mengucapkan terima kasih kepada Direktorat Riset dan Pengabdian Masyarakat, Direktorat Jenderal Penguatan Riset dan Pengembangan, Kementerian Riset, Teknologi dan Pendidikan dalam Program Pengabdian Kepada Masyarakat Tahun Anggaran 2018.

\section{DAFTAR REFERENSI}

Agrie, J., Downey, D., Boehlje, K., Harling, F.,Barnard, \& Baker, T. (1997). Food System 21 Gearing Up for the New Millenium. In Agricultural Input Industries. West Lafayette: Purdue University Cooperative Extension.

Aji, V. P., Yudhistira, R., \& Sutopo, W. (2018). Analisis Nilai Tambah Pengolahan Ikan Lemuru Menggunakan Metode Hayami. Jurnal Ilmiah Teknik Industri, 17(1): 56.

https://doi.org/10.23917/jiti.v17i1.56 11.

Amani, R., Moazen, S., Shahbazian, H., Ahmadi, K., \& Jalali, M. T. (2014). Flavonoid-rich beverage effects on lipid profile and blood pressure in diabetic patients. World Journal of Diabetes, $\quad 5(6)$ : 962. https://doi.org/10.4239/wjd.v5.i6.962

Badan Standardisasi Nasional. (2012). Tempe: Persembahan Indonesia untuk Dunia. BSN, 24. https://www.bsn.go.id/uploads/downl oad/Booklet_tempe-printed21.pdf.

Febriyanti, Irfan, M., Kalsum, U., Agribisnis, J., Pertanian, F., Lampung, U., Prof, J., \& Brojonegoro, S. (2017). Financial and Added Value Analysis of Micro and Small Scale Banana Chip Agroindustries in Metro City. 5(1): 48-56. 
Hayami, Y., Kawagoe, T., Morooka, Y., \& Siregar, M. (1987). Agricultural Marketing and Processing in Upland Java A Perspective From A Sunda Village. The CGPRT Report, 8: 44.

Herdiyandi, H., Rusman, Y., \& Yusuf, M. N. (2017). Analisis Nilai Tambah Agroindustri Tepung Tapioka Di Desa Negaratengah Kecamatan Cineam Kabupaten Tasikmalaya (Studi Kasus Pada Seorang PengusahaAgroindustri Tepung Tapioka di Desa Negaratengah Kecamatan Cineam Kabupaten Tasikmalaya). Jurnal Ilmiah Mahasiswa Agroinfo Galuh, 2(2):

81. https://doi.org/10.25157/jimag.v2i2.6 2.

Husniah, F. A., Hapsari, T. D., \& Agustina, T. (2019). Analisis Nilai Tambah Agroindustri Kerupuk Tempe di Kecamatan Puger Kabupaten Jember. Jurnal Ekonomi Pertanian Dan Agribisnis, 3(1): 195-203. https://doi.org/10.21776/ub.jepa.2019 .003 .01 .19

Pamungkassari, A. R., Marimin, M., \& Yuliasih, I. (2018). Analisis Kinerja, Nilai Tambah dan Mitigasi Risiko Rantai Pasok Agroindustri Bawang Merah. Jurnal Teknologi Industri Pertanian, 28(1): 61-74. https://doi.org/10.24961/j.tek.ind.pert .2018.28.1.61

Sulaiman, \& Natawijaya, R. S. (2018). Analisis Nilai Tambah Agroindustri Keripik Singkong (Studi Kasus Sentra Produksi Keripik Singkong Pedas di Kelurahan Setiamanah, Kecamatan Cimahi Tengah, Kota Cimahi). Jurnal Ilmiah Mahasiswa Agroinfo Galuh, 5(1): 973-986.

Wachdijono, \& Julhan, R. (2019). Analisis Peluang Laba Agroindustri Perikanan di Kecamatan Gebang, Kabupaten Cirebon, Jawa Barat Analysis of Fishery Agroindustri Profit Opportunity in Gebang Sub-district, Cirebon Regency, West Java Pada umumnya seseorang atau kelompok orang menentukan, Industria: Jurnal Teknologi dan Manajemen Agroindustri 8: 27-40. https://doi.org/10.21776/ub.industria. 2019.008.01.4.

Yoo, H., Chang, M., \& Kim, S. (2014). Fermented soybeans by Rhizopus oligosporus reduce femoral bone loss in ovariectomized rats, Nutrition Research and Practice, 8(5): 539543.

https://doi.org/10.4162/nrp.2014.8.5. 539. 